\title{
COVID-19 Pandemic and Medical Education in a Developing Country
}

\begin{abstract}
Ahmed M Abbas ${ }^{1,2 *}$, Islam Hussein Hassan ${ }^{2,3}$, Reem Sayad ${ }^{2,3}$, Mark Mohsen Kamel ${ }^{2,4}$, Fatma A Omar $^{2,4}$, Lobna Ahmed ${ }^{2,4}$, Amera S Salem ${ }^{2,3}$, Shimaa H Elsamman ${ }^{2,4}$, Alshaima Refai ${ }^{2,4}$, Andro T Fawzy $^{2,3}$, Mario S Shawky ${ }^{2,4}$, Ahmed Saeed Mostafa ${ }^{2,4}$, Ebrahim A Yousof ${ }^{2,4}$, Shimaa Salah Ali ${ }^{2,4}$, Asmaa AbouBakr ${ }^{2,4}$, Nermeen Bahaa ${ }^{2,3}$, Sherry Michael ${ }^{2,4}$, Marco Ghobrial $^{5}$, Mai E AbuElmagd ${ }^{2,4}$, Mostafa H Abdelsalam ${ }^{2,4}$, Alaa A Abdelmonsef ${ }^{2,6}$, Ghada R Fathalla ${ }^{2,6}$, Walaa R Fathalla ${ }^{2,4}$, Islam M Ebrahim ${ }^{2,3}$, Abdelrahman G Ramadan ${ }^{2,3}$, Alaa Rashad Ali ${ }^{2,4}$, Menna Allah Nashaat ${ }^{2,4}$, Heba Allah Nashaat ${ }^{2,4}$, Marina Farah Fawzy ${ }^{2,4}$, Shimaa Selim ${ }^{2,4}$, Safaa Ahmed ${ }^{2,4}$, Yasmin Ismail ${ }^{2,4}$, Yasser M Abd Elaal',4, Hanan F Fouly ${ }^{2,4}$, Naglaa Mohamed ${ }^{2,4}$, Randa Wanees Ahmed ${ }^{2,4}$, Sara Magdy ${ }^{2,4}$, Amera Imam ${ }^{2,4}$, Nourhan Mahmoud ${ }^{2,4}$, Zeinab Y Zaki ${ }^{2,4}$, Salma A Samy ${ }^{2,4}$, Shrouk Gad ${ }^{2,4}$, Aya Shaban $^{2,4}$, Mohamed Ashraf Salah ${ }^{2,4}$, Mohamed M Abdelkarem ${ }^{2,4}$, Areej A Khamees ${ }^{2,3}$, Aya Abdelnasser ${ }^{2,4}$, Samar Mamdouh Mostafa ${ }^{2,4}$, Alaa Bazeed Dardeer ${ }^{2,4}$, Ahmed S Sedik ${ }^{2,4}$, Hossam Aldein Samir ${ }^{2,4}$, Mahmoud M Saad ${ }^{2,4}$, Zakria Y Elessemy ${ }^{2,4}$, Karim 0 Sleem $^{2,4}$, Mohammed H Abdelhafez ${ }^{2,4}$, Eshak N Youssef ${ }^{2,4}$, Zeinab M Bakr ${ }^{2,4}$, Micheal Mohab Nady ${ }^{2,7}$, Mohamed Salah Abdo $^{2,3}$, Mohamed 0 Omar ${ }^{2,3}$, Mahmoud Kamel ${ }^{2,4}$, Hajer Y Moustafa ${ }^{2,3}$, Hala Hashem ${ }^{2,3}$, Hagar A Elotifiy $^{2,3}$, Areej A Abdelaziz ${ }^{2,3}$, Tarek M Essa ${ }^{2,3}$, Fatma A El-Saaid Monib ${ }^{2,3}$, Nehal Gamal Omar ${ }^{2,3}$, Moaiad Eldin A Mohamed ${ }^{2,3}$, Andrew Nasseh Hafeez ${ }^{2,3}$, Esraa Atif Hassan ${ }^{2,4}$, Ahlam 0 Ali ${ }^{2,4}$, AlBatool M AlMahdy ${ }^{2,4}$, Alya O Mohamed ${ }^{2,4}$, Shorouk M Adel ${ }^{2,4}$, Sarah Khaled Fahmi ${ }^{2,3}$, Abeer Abdel-Fattah ${ }^{2,4}$, Mariam Salah Moris ${ }^{2,8}$ and Safaa K Fathy ${ }^{2,4}$
\end{abstract}

\footnotetext{
${ }^{1}$ Department of Obstetrics \& Gynecology, Faculty of Medicine, Assiut University, Egypt

${ }^{2}$ Covid-19 Research of Assiut University Association (CORAUNA) group

${ }^{3}$ Undergraduate student, Faculty of Medicine, Assiut University, Egypt

${ }^{4}$ House-officer, Faculty of Medicine, Assiut University, Egypt

${ }^{5}$ Senior House-officer, The Queen Elizabeth University Hospital, United Kingdom

${ }^{6}$ Undergraduate student, Faculty of Pharmacy, Assiut University, Egypt

${ }^{7}$ Resident, Department of pediatrics and Neonatology, Ahmed Maher Teaching Hospital, Egypt

${ }^{8}$ General Practitioner and Postgraduate, Faculty of Medicine, Assiut University, Egypt
}

*Corresponding author: Ahmed M Abbas, Department of Obstetrics and Gynecology, Assiut University, Egypt, Women Health Hospital, 71511, Assiut Egypt.

To Cite This Article: Ahmed MA, Islam Hussein H, Reem S, Mark Mohsen K, Lobna A, et al., COVID-19 Pandemic and Medical Education in a Developing Country. 2020 - 9(4). AJBSR.MS.ID.001408. DOI: 10.34297/AJBSR.2020.09.001408.

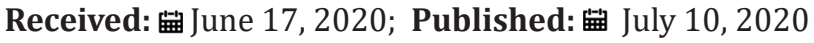

\section{Short Communication}

In March 2020, the World Health Organization considered coronavirus disease-2019 (COVID-19) as a worldwide pandemic [1]. This leads to serious effects on medical education in medical schools. Medical students are potentially susceptible to COVID-19

owing to their contact with in-patients during the clinical teaching classes and their common rotation between the hospital depart ments [2]. Closure of medical schools and continuing the educational process from home for both staff and students became urgent to ensure social distancing. 
As the COVID-19 problem evolved in Egypt, education in the whole universities was suspended for several weeks. The classes for all six years of the undergraduate medical teaching were stopped. This had a detrimental effect on medical students due to less exposure for clinical teaching classes and patient examination. Clinical teaching and exams using live patients are a crucial part of a medical student's education. Integration of information technology into the teaching and problem-based learning (PBL) methodologies at our medical schools was the solution. Moreover, all medical conferences and presentations carried out by the students were canceled. This affected student' skills and experiences as these methods are used to build up medical student curriculum vitae.

The following alternative modalities for classical teaching were advocated to keep the students on track with the medical curriculum. Streamed online lectures and prepared online modules were used for delivery of the theoretical lectures [3]. PowerPoint presentations with the lecturer's voice were recorded and made available on each faculty website. This was an excellent substitute for collection of large group of students in a lecture hall with high possibility of viral transmission. Besides that, it avoids the rush of the students at 8:00 am to attend the lectures.

In the past decade, many academic institutions worldwide undertook curricular reforms to promote flipped classrooms and active learning that facilitated a transition of preclinical learning to an entirely online exercise.3 Previous study showed a prior evidence that these active techniques are preferred by trainees and can help develop a valuable learning skills in undergraduate medical students [4]. Many faculties use customizable cloud-based learning management platforms such as "Moodle" to make the online lectures more accessible and organized [5].

Additionally, PBL tutorials and small group sessions have been replaced with interactive Webinars through web conferencing platforms with the medical staff. Our medical school staff used "Zoom" to be a real interaction between them and their students and by this way they can provide information better. This site has already proven to be effective in attracting large number of medical students [6]. One of the most effective ways which use web conferencing is the flipped classroom, in which there is providing learning recourses like videos, voices, articles, pictures, online books and YouTube links before the class then the class will be only for the discussion [5]. The main advantage of these learning resources is the easy access from smart phones while staying safe at home.

High-fidelity simulation models were used for recording videos to facilitate student learning and training on the clinical skills [7]. This offers the opportunity for demonstration of essential procedural clinical skills and training in interpersonal communication. Social media can provide an easily accessible and interesting method for medical education specially Twitter that play an important role in many clinicians' continued education, and online journal clubs or "tweetorials" can enable residents and medical students to interact with world leaders in their areas of interest [8]. Telehealth has become an important factor to develop health care during COVID-19 pandemic so engagement of medical students in this method will be very beneficial for them. Through telehealth, medical students can participate in the virtual room to participate in history taking and to observe virtual physical examination [9].

Finally, regular assessments of student attainment of medical courses were mainly depending on large scale examinations. Using the online tools and platforms was the solution to carry out a formative assessment of their knowledge. The use of online medical education and adapting to open book examination (OPE) will have an impact on medical students [10]. It will reduce the stress symptoms and anxiety during the COVID-19 pandemic instead of exam-hall settings. Our recommendations for final year's exams are to be simplified and consistent with testing necessary learning objectives. Patients will not be allowed to be part of clinical exams and substitution with virtual models will be the best way for testing the clinical and procedural skills.

\section{Declaration of Interest}

The authors state that there are no conflicts of interest.

\section{Reference}

1. Domenico Cucinotta, Maurizio Vanelli (2020) WHO Declares COVID-19 a Pandemic. Acta bio-medica 91(1): 157.

2. Ahmed H, Allaf M, Elghazaly H (2020) COVID-19 and medical education. Lancet Infect Dis 20(7): 777-778.

3. Augestad KM, Lindsetmo RO (2009) Overcoming distance: Videoconferencing as a clinical and educational tool among surgeons. World J Surg 33(7): 1356-1365.

4. Rose S (2020) Medical Student Education in the Time of COVID-19. JAMA 323(21): 2131-2132.

5. Kaup S, Jain R, Shivalli S, Pandey S, Kaup S (2020) Sustaining academics during COVID-19 pandemic: The role of online teaching-learning. Indian J Ophthalmol 68(6): 1220-1221.

6. Kay D, Pasarica M (2019) Using technology to increase student (and faculty satisfaction with) engagement in medical education. Adv Physiol Educ 43(3): 408-413.

7. Abrahamson SD, Canzian S, Brunet F (2006) Using simulation for training and to change protocol during the outbreak of severe acute respiratory syndrome. Crit Care 10(1).

8. Thangasamy IA, Loeb S, Sathianathen NJ, Leveridge M, Stork B, et al. (2019) Evaluating the effectiveness of an online journal club: Experience from the International Urology Journal Club. Eur Urol Focus.

9. Theoret C, Ming X (2020) Our education, our concerns: The impact on medical student education of COVID-19. Med Educ 54(7): 591-592.

10. Broyles IL, Cyr PR, Korsen N (2005) Open book tests: Assessment of academic learning in clerkships. Med Teach 27(5): 456-462. 